\title{
Cellular src Gene Product Detected in the Freshwater Sponge Spongilla lacustris
}

\author{
ANGELIKA BARNEKOW ${ }^{1 *}$ AND MANFRED SCHARTL ${ }^{2}$ \\ Institut für Medizinische Virologie ${ }^{1}$ and Genetisches Institut ${ }^{2}$ der Justus-Liebig-Universität Giessen, D-6300 Giessen, \\ Federal Republic of Germany
}

Received 24 October 1983/Accepted 6 March 1984

\begin{abstract}
Serum from Rous sarcoma virus tumor-bearing rabbits immunoprecipitated from extracts of the freshwater sponge Spongilla lacustris a tyrosine-specific protein kinase with characteristics similar to the chicken $p$ p $60^{\text {c-src }}$ kinase activity. An immune competition assay confirmed the relationship between the protein from sponges and viral $\mathrm{pp} 60^{\mathrm{v}-\mathrm{src}}$.
\end{abstract}

The transforming gene of Rous sarcoma virus (RSV), vsrc, codes for a 60,000 -dalton phosphoprotein, $\mathrm{pp} 60^{\mathrm{v}-s r c}(1)$, which functions as a tyrosine-specific protein kinase $(2,6)$. The corresponding normal cellular counterpart, c-src, also codes for a protein, pp60-src, which shares structural and functional homology with viral pp60 $0^{\mathrm{v}-\mathrm{src}}$. Sequences homologous to v-src are present in the genomes of all vertebrates tested so far $(7,9,13-15)$ and have been detected in the genus Drosophila (12). In this communication, we demonstrate the presence of a protein immunologically and functionally related to pp $60^{\mathrm{v}-s r c}$ in the freshwater sponge Spongilla lacustris. Sponge cell extracts were tested for a tyrosine-specific kinase activity similar to the avian pp60src. associated kinase activity. It was shown that the immunoglobulin $\mathrm{G}$ heavy chain of tumor-bearing rabbit (TBR) serum could be phosphorylated upon reaction (11) with a sponge cell extract, whereas the reaction with normal rabbit serum was negative (Fig. 1a). That the ${ }^{32} \mathrm{P}$-labeled 53,000 (53K) band was indeed the heavy chain of immunoglobulin $G$ was established by running parallel portions of each sample with and without mercaptoethanol, so that under nonreducing conditions, a high-molecular-weight band of $150 \mathrm{~K}$ could be observed (Fig. 1a). To prove that the kinase reaction observed actually utilized the same antibodies in TBR serum as those which took part in the reaction with pp60 ${ }^{v-s r c}$, an assay was performed in which a limiting amount of serum was reacted with heat-inactivated $\left(50^{\circ} \mathrm{C}\right.$ for $\left.40 \mathrm{~min}\right)$ sponge extracts (ca. $0.2 \mathrm{mg}$ of protein) before the addition of RSVinfected chicken cell lysates, followed by an in vitro kinase reaction (10). Preincubation with the heat-inactivated sponge extracts greatly reduced the pp60 ${ }^{v-s r c}$ kinase reaction (Fig. 1b). Finally, the $53 \mathrm{~K}$ product of the in vitro protein kinase reaction seen in Fig. la was cut out of the gel and eluted, and phosphoamino acids were analyzed by the method of Hunter and Sefton (6). The phosphorylated immunoglobulin G heavy chain is exclusively labeled in phosphotyrosine (Fig. 1c).

Immunoprecipitations with increasing amounts of TBR serum and a constant amount of sponge extract resulted in a maximum kinase activity with $5 \mu \mathrm{l}$ of serum, whereas after the time dependence of the phosphorylation of heavy chain a

\footnotetext{
* Corresponding author.
}

maximum incorporation was revealed between 4 and 5 min (Fig. 1d and e).

With respect to all reaction characteristics, the protein kinase activity as detected in sponge extracts could not be distinguished from the activity associated with the chicken cell pp60-src (A. Barnekow and H. Bauer, Biochim. Biophys. Acta, in press). Thus, it was reasonable to expect homologous nucleic acid sequences. To determine whether the cellular homolog, c-src, of the transforming gene of RSV, $\mathrm{v}$-src, is present in the genome of sponges, EcoRI-digested sponge DNA was hybridized to a src-specific probe by using hybridization conditions of moderate stringency. A single fragment of ca. 14.0 kilobases was found to contain sequences homologous to the v-src gene (Fig. 2A). Blot hybridization of polyadenylated RNA indicated that the cellular src-related sequences are transcribed into a single mRNA of ca. 2.2 kilobases in size (Fig. 2B).

Previous systematic studies on the expression of c-src in metazoa gave evidence that the first organisms showing a TBR serum-reactive protein kinase activity during phylogenesis are the sponges (10). The present communication presents detailed evidence for such a protein kinase activity in $S$. lacustris. The immunoprecipitating heavy chain becomes phosphorylated, the phosphorylation occurs on tyrosine,

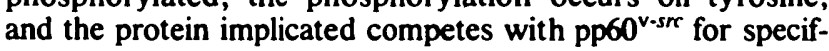
ic antibodies. Altogether, the data indicate the presence in sponges of a protein largely homologous to pp60 6 c-src. Owing to the problems both of labeling sponges and of the small amounts of material, it has so far not been possible to detect the protein directly or to establish its molecular weight, but Southern blot analysis revealed related sequences in the Spongilla DNA, and expression as RNA could also be detected. Conservation of structural features of proteins across phylogenetic groups has been demonstrated for several proteins: collagen first appears during phylogenesis in sponges (4), and fibronectin has also been shown at this early stage of phylogenesis (8). We have demonstrated in serum from newborn rabbits bearing RSV tumors a tyrosine-specific protein kinase activity immunologically and functionally homologous to the pp60 ${ }^{\mathrm{v}-\mathrm{src}}$ in $S$. lacustris. Parallel experiments performed with Saccharomyces cerevisiae and Tetrahymena thermophila revealed no similar protein kinase activity reactive with TBR serum, and no homology was detectable after hyridization on Southern blots. Hence, these data represent the most distant phylogenetic extension of src gene product homology. 


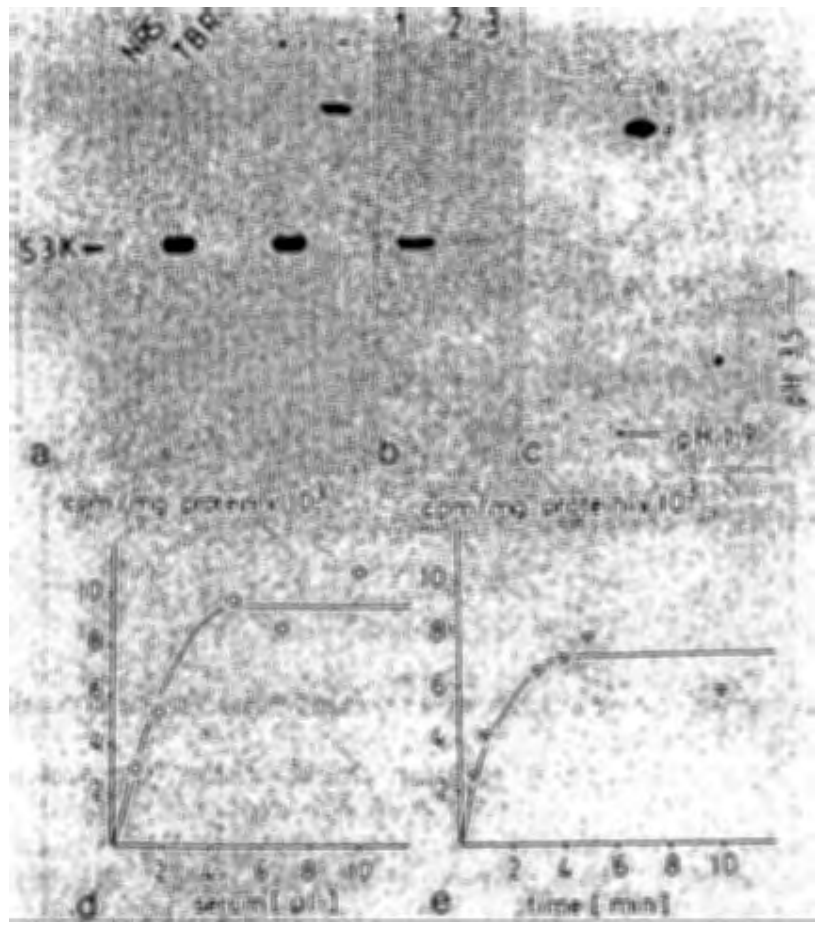

FIG. 1. Characterization of the phosphorylated $53 \mathrm{~K}$ product of an in vitro protein kinase reaction on TBR serum immunoprecipitates from $S$. lacustris extracts. (a) Approximately $100 \mathrm{mg}$ of $S$. lacustris was lysed in extraction buffer by methods described elsewhere (11), and immunoprecipitation was performed by using either chicken pp60 $0^{\text {c-src }}$-reactive TBR serum (1) or normal rabbit serum (NRS). A kinase reaction was performed as previously described (11), and the products were analyzed on sodium dodecyl sulfate-polyacrylamide gels. Parallel reaction products, using TBR serum, were electrophoresed side-by-side with $(+)$ mercaptoethanol under reducing conditions or without $(-)$ mercaptoethanol to demonstrate that the reaction substrate has structural properties like immunoglobulin G. (b) A blocking assay was performed to show that extracts of $S$. lacustris could compete with pp60 $60^{v-s r c}$ for available antibodies. Track 1, Extract of Schmidt-Ruppin RSV (subgroup A)infected chicken embryo cells immunoprecipitated by using limiting amounts of TBR $(2 \mu \mathrm{l})$, followed by an in vitro kinase reaction. Track 2, Samples were prepared as for track 1 except that TBR serum was prereacted with ca. $0.2 \mathrm{mg}$ of $S$. lacustris extracts (heat inactivated [10] at $50^{\circ} \mathrm{C}$ for $40 \mathrm{~min}$ ) before the addition of the RSV. infected chicken embryo cell lysate. Track 3, Protein kinase reaction of heat-inactivated sponge extract to demonstrate loss of activity. (c) The 53K reaction product from (a) was eluted from the gels and hydrolyzed, and the phosphoamino acids were analyzed by the method of Hunter and Sefton (6). (d and e) Quantitative data for the protein kinase reaction were obtained by varying the amounts of TBR serum and the reaction times. The reactions were performed as above, the $53 \mathrm{~K}$ reaction products were cut of the gels and solubilized, and the radioactivity was measured in a liquid scintillation counter.

We thank H. Bauer and F. Anders for helpful suggestions, R. R Friis and $S$. Robertson for critically reading the manuscript, $R$. Gallo for providing pBR322-cloned SR-A2, M. Gessler for preparing the src-specific fragment for the hybridization studies, D. Gallwitz for yeast DNA, H.-M. Seyfert for Tetrahymena DNA, E. Ossendorf and Chr. Reitz for technical assistance, and A. Becker for typing the manuscript.

This work was supported by the Deutsche Forschungsgemeinschaft, Sonderforschungsbereiche 47 "Virologie" and 103 "Zellenergetik und Zelldifferenzierung."

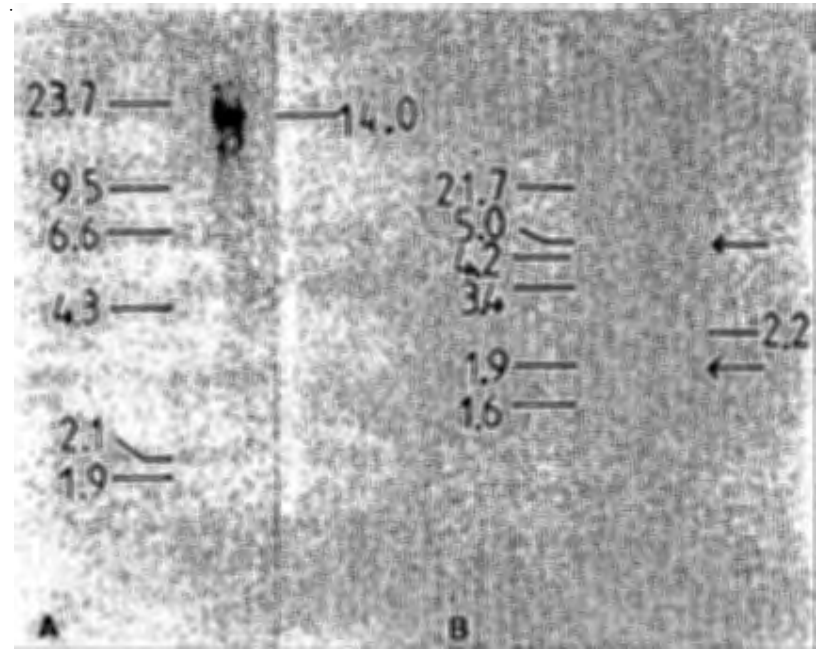

FIG. 2. Autoradiograms showing the hybridization of $S$. lacus tris DNA (A) and RNA (B) to radioactive probe prepared with nick translation from a src-specific fragment of recombinant DNA-cloned RSV (3). The 0.6-kilobase Pst fragment F of pSRA-2 (3) served as the $s r c$-specific probe and was prepared from restriction enzyme digests of the plasmid by polyacrylamide gel electrophoresis. (A) EcoRI-digested S. lacustris DNA $(15 \mu \mathrm{g})$ was fractionated on a $0.8 \%$ agarose gel, transferred to nitrocellulose, and hybridized to a v-srcspecific probe under conditions of $35 \%$ formamide at $42^{\circ} \mathrm{C}$. Washing was performed at $68^{\circ} \mathrm{C}$ in $1 \times \mathrm{SSC}(1 \times \mathrm{SSC}$ is $0.15 \mathrm{M} \mathrm{NaCl}$ plus $0.015 \mathrm{M}$ sodium citrate). Molecular weights were determined in parallel by using restriction fragments of $\lambda$ DNA. (B) Polyadenylated $S$. lacustris RNA $(20 \mu \mathrm{g})$, extracted by the method of Harding et al. (5), was fractionated on formaldehyde-agarose gels, transferred to a hybridization membrane, and hybridized to the v-src-specific probe under conditions of $35 \%$ formamide at $42^{\circ} \mathrm{C}$. Washing was performed at $50^{\circ} \mathrm{C}$ in $1 \times \mathrm{SSC}$. Molecular weights were determined in parallel by using restriction fragments of $\lambda$ DNA and $18 S$ and $28 S$ RNA species (arrows)

\section{LITERATURE CITED}

1. Brugge, J. S., and R. L. Erikson. 1977. Identification of a transformation-specific antigen induced by avian sarcoma virus. Nature (London) 269:346-348.

2. Collett, M. S., and R. L. Erikson. 1978. Protein kinase activity associated with the avian sarcoma virus src gene product. Proc. Natl. Acad. Sci. U.S.A. 75:2021-2024.

3. DeLorbe, W. J., P. A. Lucin, H. M. Goodman, H. E. Varmus, and J. M. Bishop. 1980. Molecular cloning and characterization of avian sarcoma virus circular DNA molecules. J. Virol. 36:5061.

4. Garrone, R. 1978. Phylogenesis of connective tissue. In L. Robert (ed.), Frontiers of matrix biology, vol. 3. S. Karger. Basel.

5. Harding, J. D., R. J. MacDonald, A. E. Przybula, J. M. Chirgwin, R. L. Pictet, and M. W. Rutter. 1977. Changes in the frequency of specific transcripts during development of the pancreas. J. Biol. Chem. 252:7391-7397.

6. Hunter, T., and B. M. Sefton. 1980. Transforming gene product of Rous sarcoma virus phosphorylates tyrosine. Proc. Natl. Acad. Sci. U.S.A. 77:1311-1315.

7. Karess, R. E., W. S. Hayward, and H. Hanafusa. 1979. Cellular information in the genome of recovered avian sarcoma virus directs the synthesis of transforming protein. Proc. Acad. Sci. U.S.A. 76:3154-3158.

8. Labat-Robert, J., L. Robert, C. Auger, C. Lethias, and R. Garrone. 1981. Fibronectin-like protein in Porifera: its role in cell aggregation. Proc. Natl. Acad. Sci. U.S.A. 78:6261-6265.

9. Parker, R. C., H. E. Varmus, and J. M. Bishop. 1981. Cellular homologue $(c-s r c)$ of the transforming gene of Rous sarcoma 
virus: isolation mapping, and transcriptional analysis of c-src and flanking regions. Proc. Natl. Acad. Sci. U.S.A. 78:58425846.

10. Rübsamen, H., R. R. Friis, and H. Bauer. 1979. Src gene product from different strains of avian sarcoma virus: kinetics and possible mechanism of heat inactivation of protein kinase activity from cells infected by transformation-defective, temperature-sensitive mutant, and wild-type virus. Proc. Natl. Acad. Sci. U.S.A. 76:967-971.

11. Schartl, M., and A. Barnekow. 1982. The expression in eukaryotes of a tyrosine kinase which is reactive with pp60 ${ }^{\text {r-sre }}$ antibodies. Differentiation 23:109-114.

12. Shilo, B.-Z., and R. A. Weinberg. 1981. DNA sequences homolo- gous to vertebrate oncogenes are conserved in Drosophila melanogaster. Proc. Natl. Acad. Sci. U.S.A. 78:6789-6792.

13. Spector, D. H., B. Baker, H. E. Varmus, and J. M. Bishop. 1978. Nucleotide sequences related to the transforming gene of avian sarcoma virus are present in DNA of uninfected vertebrates. Proc. Natl. Acad. Sci. U.S.A. 75:4102-4106.

14. Spector, D. H., B. Baker, H. E. Varmus, and J. M. Bishop. 1978. Characterization of cellular RNA related to the transforming gene of avian sarcoma viruses. Cell 13:382-386.

15. Spector, D. H., K. Smith, T. Padgett, P. McCombe, D. RoullandDussoix, D. Moscovici, H. E. Varmus, and J. M. Bishop. 1978. Uninfected avian cells contain RNA related to the transforming gene of avian sarcoma virus. Cell 13:371-379. 